\title{
Building a better future for youth: Learning from experience and evidence
}

World Health Organization

Population Council

Family Health International

Follow this and additional works at: https://knowledgecommons.popcouncil.org/departments_sbsr-rh How does access to this work benefit you? Let us know!

\section{Recommended Citation}

"Building a better future for youth: Learning from experience and evidence." Washington, DC: World Health Organization, Population Council, and Family Health International, 2006. 


\section{Building a Better Future for Youth: Learning from Experience and}

Evidence

Africa Regional Forum on Youth Reproductive Health and HIV June 6-9, 2006

Dar es Salaam, United Republic of Tanzania

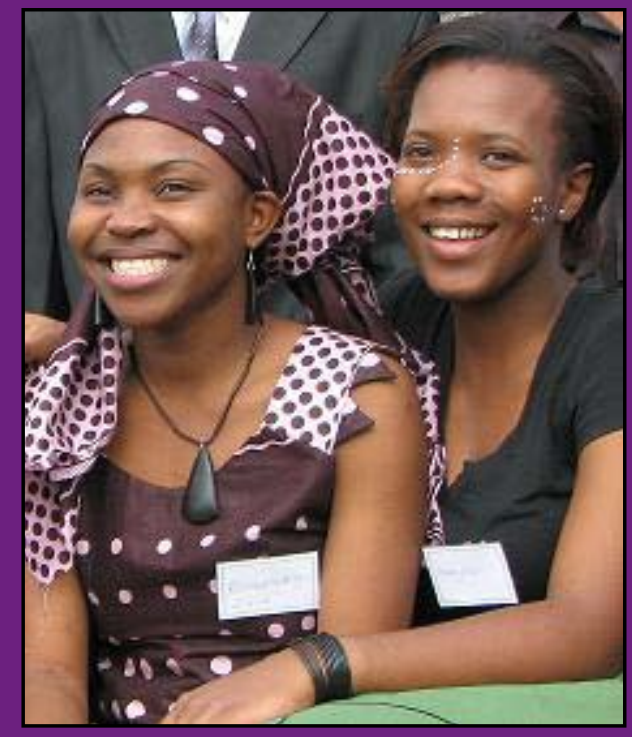

Department of Reproductive Health and Research, World Health Organization

Frontiers in Reproductive Health, Population Council

YouthNet, Family Health International

World Health Organization

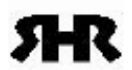

Reproductive Health and Research
(1) Population Council FRONTIERS IN REPRODUCTIVE HEALTH

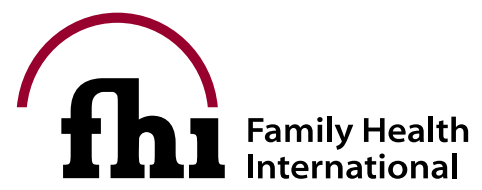

YouthNet

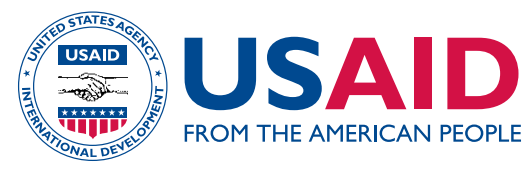





\title{
Building a Better Future for Youth: Learning from Experience and Evidence
}

\author{
Africa Regional Forum on \\ Youth Reproductive Health and HIV \\ June 6-9, 2006 \\ Dar es Salaam, United Republic of Tanzania
}

Department of Reproductive Health and Research, World Health Organization

Frontiers in Reproductive Health, Population Council

YouthNet, Family Health International

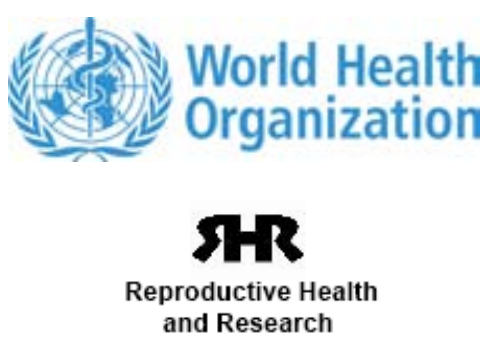

(2) Population Council
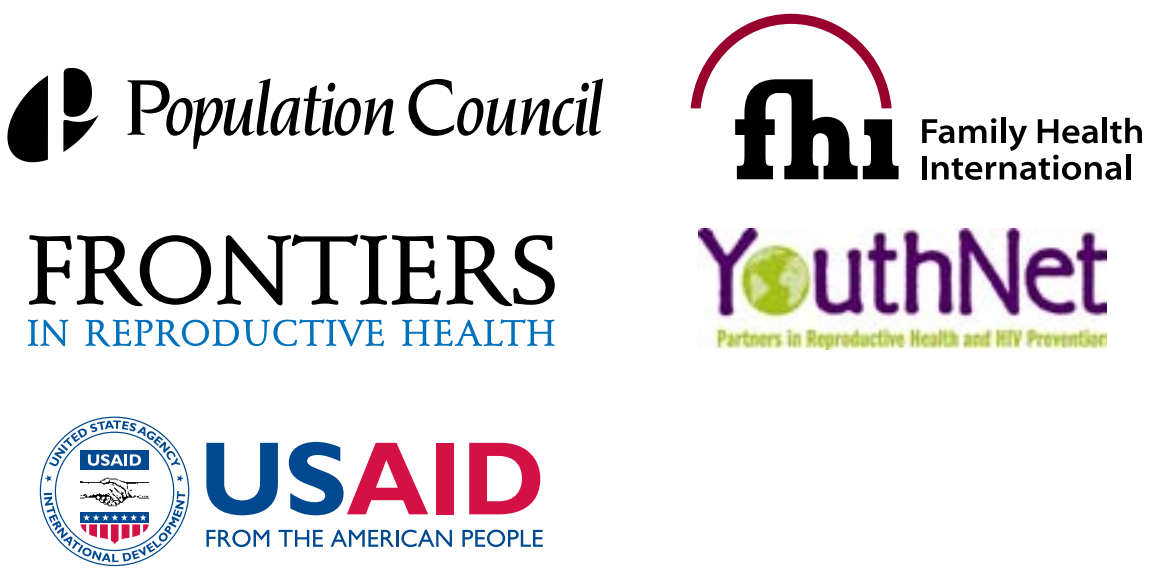


\section{Acknowledgments}

The Forum was organized with support from the U.S. Agency for International Development and the World Health Organization. Shawn Malarcher prepared the report in consultation with Sarah Campbell, Venkatraman Chandra-Mouli, Bill Finger, Maxwell Marx, Tonya Nyagiro, Laura Raney, Ed Scholl, Jane Schueller, Iqbal Shah, Mercedes Torres, and John Townsend.

Special thanks to Robert Heidel for editing and Sherry Hutchinson and Sarah Campbell for design and layout of this publication.

World Health Organization
Established in 1948, the World Health Organization (WHO) is a specialized agency of the United Nations. Its objective, as set out in its Constitution, is the attainment by all peoples of the highest possible level of health. Health is defined in WHO's Constitution as a state of complete physical, mental and social well-being and not merely the absence of disease or infirmity.

\section{MR}

Reproductive Health and Research

The Department of Reproductive Health and Research (RHR) has set itself the mission of helping people to lead healthy sexual and reproductive lives. In pursuit of this mission the Department endeavours to strengthen the capacity of countries to enable people to promote and protect their own health and that of their partners as it relates to sexuality and reproduction, and to have access to and receive quality reproductive health services when needed.

\section{(Population Council}

The Population Council is an international, nonprofit, nongovernmental organization that seeks to improve the well-being and reproductive health of current and future generations around the world and to help achieve a humane, equitable, and sustainable balance between people and resources. The Council conducts biomedical, social science, and public health research and helps build research capacities in developing countries. Established in 1952, the Council is governed by an international board of trustees. Its New York headquarters supports a global network of regional and country offices.

FRONTIERS Frontiers in Reproductive Health (FRONTIERS) is funded by the U.S. Agency for International IN REPRODUCTIVE HEALTH

Development (USAID) under the terms of Cooperative Agreement Number HRN-A-00-9800012-00 and led by the Population Council in collaboration with Family Health International. FRONTIERS staff and collaborating organizations conduct operations research in Africa, Asia, Eastern Europe, and Latin America and the Caribbean.

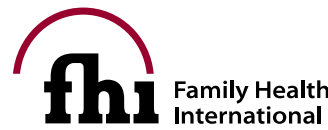

Family Health International (FHI) is dedicated to improving lives, knowledge and understanding worldwide through a highly diversified program of research, education and services in family health. Since 1971, FHI has worked with governments and communities to meet the public health needs of some of the world's most vulnerable people. FHI has offices in 38 countries and manages research and field activities in more than 70 countries. approaches that address reproductive health and HIV/AIDS prevention for youth at national, regional, and international levels. The program is funded by USAID through a five-year cooperative agreement awarded in October 2001 to FHI, in partnership with CARE USA and RTI International.

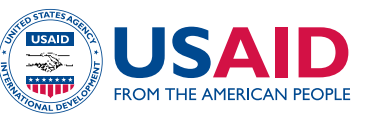

Published in 2006.

Both Frontiers in Reproductive Health and YouthNet are funded by USAID. This publication was made possible through support provided by USAID.The opinions expressed herein do not necessarily reflect the views of USAID.

Suggested citation: "Building a better future for youth: Learning from experience and evidence," Africa Regional Forum on Youth Reproductive Health and HIV, 6-9 June 2006, Dar-es-Salaam, Tanzania. Washington, DC: World Health Organization, Population Council, and Family Health International.

(C) 2006 World Health Organization, Population Council, and Family Health International.

This publication may be reproduced in whole or in part without permission of Population Council provided full source citation is given and the reproduction is not for commercial purposes. 


\section{Table of Contents}

Introduction

Trends in youth behavior and environment

Services for youth

School- and curriculum-based education

Peer education

Supportive environments

Monitoring and evaluation of youth programs

Youth participation

Recommendations

Conclusions

Appendix 1: Participants

Appendix 2: Presentations

Appendix 3: Roundtable discussions

Appendix 4: Key documents

Appendix 5: Additional resources

SANKOFA

"Return and get it" 



\section{Introduction}

On June 6-9, 2006 the World Health Organization's Department of Reproductive Health and Research (RHR), the Frontiers in Reproductive Health (FRONTIERS) Program of the Population Council, and the YouthNet Program (YouthNet) of Family Health International (FHI) sponsored a regional forum on critical issues in youth reproductive health and HIV programs in sub-Saharan Africa. These three organizations work at the forefront of youth reproductive health and HIV research; their combined contributions represent one of the largest and most up-to-date bodies of research and program evidence on youth.

The objectives of the Africa Regional Forum on Youth Reproductive Health and HIV were to:

- share the latest research results and program evidence;

- share findings and methodologies of promising interventions for youth and identify new programs and techniques;

- identify gaps in existing research, programs, and policies in youth reproductive health and HIV prevention; and

- explore monitoring and evaluation methodologies and desired outcomes for youth programs.

\section{"This forum is really about the future with young people, for young people." —John Townsend, Population Council}

The meeting format involved plenary sessions, roundtable discussions, and working groups. Plenary sessions offered participants background information and opportunities to discuss characteristics of youth both globally and in Africa, as well as to explore new ideas and methods for monitoring and evaluating youth reproductive health and HIV programs. Roundtable discussions allowed small groups of participants to engage in informal discussions on specific areas of work. Topics were selected by the presenter and usually related to ongoing activities. During these sessions, presenters described their experience and received advice from other forum participants on addressing hurdles in implementation. A complete list of roundtable discussions is included in Appendix 3. Concurrent group sessions - which made up the bulk of the agenda - offered participants time for indepth presentation and discussion on the research, policy, and program issues associated with:

- Youth reproductive health and HIV services;

- School- and curriculum-based education, and peer education; and

- Supportive and enabling environments for youth.

A complete list of session presentations is included in Appendix 2.

The three organizations engaged a broad range of participants to ensure that technical issues were interpreted and viewed from a diversity of perspectives. Approximately 90 national, regional, and international researchers, donors, program managers, youth, and policymakers from nine African countries participated in the forum. A complete list of participants by country is included in Appendix 1. Involvement of high-level policymakers and donors focused attention on moving programs and research from the pilot stage to national coverage. Youth participants provided valuable insight into the difficulties involved in identifying and addressing 
the needs of young people. Mama Salma Kikwete, the First Lady of Tanzania, officially opened the proceedings by reminding participants of the enormous scope and importance of their task, stating that young people account for a third of the population in sub-Saharan Africa. She drew attention to the challenges facing youth, including high rates of HIV, early pregnancy, unsafe abortions, and child marriages.

This report summarizes the key content of presentations and indicates the breadth of participant discussion. The report is organized around central themes of the forum. Presentations and forum resources are available via website at http://www.fhi. org/en/Youth/YouthNet/NewsEvents/index. $\mathrm{htm}$. Lists of key documents and additional resources are presented in Appendixes 4 and 5.

\section{Trends in youth} behavior and environment

Youth represent a large and growing demographic group globally. The challenges they face in becoming productive, healthy adults, especially in sub-Saharan Africa, are numerous. Sexually active youth in the region have low contraceptive-use rates and limited knowledge about reproductive health, and they account for a high proportion of the region's new HIV infections, maternal mortality rates, and unmet need for reproductive health information and services. These circumstances can be attributed to a number of social, cultural, economic, and gender-related factors.
The recent publication Growing Up Global: The Changing Transitions to Adulthood in Developing Countries ${ }^{1}$ examines key factors influencing how young people prepare for adult roles. Cynthia B. Lloyd, director of social science research at the Population Council and chair of the National Research Council and Institute of Medicine panel, highlighted the findings from the education and health sector. Lloyd emphasized cultural and socioeconomic factors altering the environment in which young people today make the transition to adulthood. These factors include globalization, improvements in technology, increased democratization, shifts in age distribution, increasing numbers (especially girls) enrolled in school, and changes in health - both positive and negative.

Growing Up Global emphasizes the key role of educational institutions in the lives of adolescents. Growth in school attendance and grade attainment has been unprecedented on a global scale, and the gender gap in enrollment is closing rapidly. As a result, school has become an increasingly important setting for reaching young people and shaping their transition to adulthood. However, the growing number of students enrolled in school has strained fragile education systems in many countries. International standardized tests assessing basic literacy and math skills document a decrease in student achievement, leaving young people unprepared for skilled employment. Even with record-high attendance rates, large differentials in school attendance by income

\footnotetext{
${ }^{1}$ The producers of this book, The National Research Council and the Institute of Medicine, convened a 15-member panel of experts to examine the changing transition to adulthood in developing countries, with a particular emphasis on gender, and the policy implications of these changes. The National Research Council and the Institute of Medicine are private, nonprofit institutions that provide science and health policy advice under a congressional charter. The National Research Council is the principal operating arm of the National Academy of Sciences and the National Academy of Engineering. The full report is available at: http://www.nap. edu/books/030909528X/html/
} 
and residence persist, with adolescents from poor families and rural areas lagging behind those from better-off families and from cities.

\section{"Youth are not the same. They cannot be copied and pasted."}

-Sudi Biko Matara, I Choose Life

Therefore, adolescent programs focused exclusively on school-based factors are likely to miss a significant and vulnerable portion of youth.

Globally, adolescence is a time of good health. Nevertheless, AIDS is the leading cause of death among adolescents, especially girls in Africa. The role of HIV and AIDS

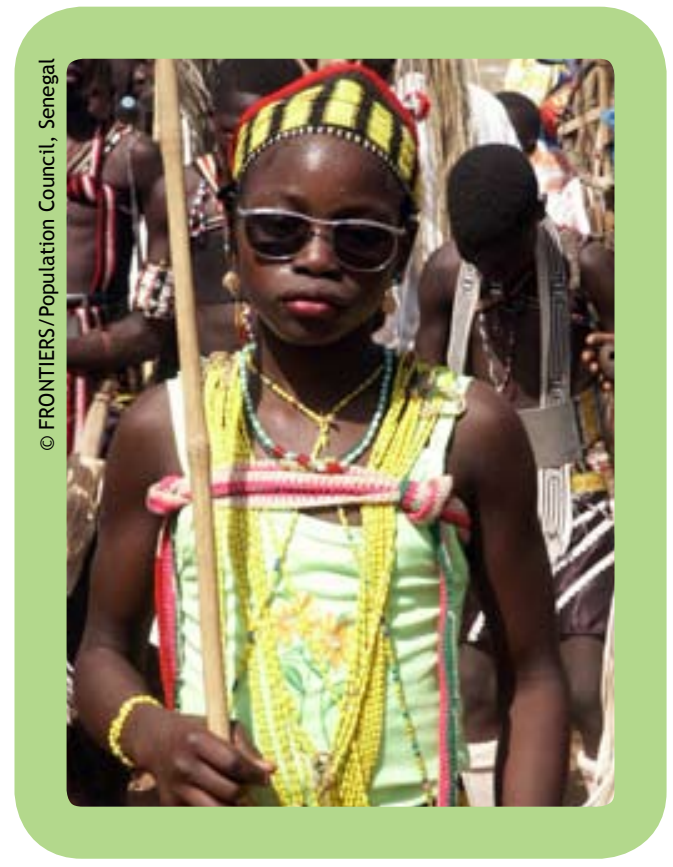

Young girl in Burkina Faso overshadows the impact of other factors on adolescent health, such as maternal mortality for girls and violence among boys. School enrollment continues to play a protective role in sexual and reproductive health. Enrolled students are less likely to be sexually active, and if sexually active, students are twice as likely to use contraception as non-students. Growing Up Global also identified an important change in the context of sexual initiation. Data show that first sex is increasingly likely to occur before marriage as a result of the increasing age at which marriage takes place. This is supported by the finding that overall marriage delays have not led to a delay in the age of sexual initiation.

The sexual and reproductive health of youth was explored in greater detail in the presentation on trends in protective behaviors among African women by John Cleland, from the Centre for Population Studies, London School of Hygiene and Tropical Medicine. The presentation summarized findings from a secondary analysis of Demographic and Health Survey data from 1993 to 2001 in 18 African countries. ${ }^{2}$ The study examined trends in abstinence, secondary abstinence, and condom use among married and unmarried women. The authors found very little change in abstinence rates among unmarried women. Approximately 60 percent of single women aged 15-24 reported no sexual experience. Rates of secondary abstinence, measured by the percentage of single, sexually experienced women reporting no sex in the last three months, showed a slightly upward trend.

Current use of any contraceptive method among single women has increased overall. Use of non-barrier methods remains constant, traditional method use has decreased, and condom use has increased substantially. In 13 of the 18 African countries, the increase in condom use is statistically significant. Condom use is growing at 14 percent per decade, which is about the same as the rate of increase in contraceptive use in the developing world. Nearly all women obtain condoms through shops and pharmacies, rather than from clinics. Contraceptive use among married women is also on the rise; however, most of this increase is in use of non-barrier methods and there has been little change in condom use among this population.

\footnotetext{
${ }^{2} \mathrm{~A}$ summary of this study is scheduled for publication in The Lancet in late 2006. 
Understanding the environment in which young people live is essential to designing programs that reach youth and meet their needs. Poverty and isolation, factors that increase the vulnerability of adolescents, were frequent themes in forum discussions and presentations. Even with poverty rates declining worldwide, the percentage of young people in Africa growing up in poverty is on the rise. Richard Mabala, from UNICEF Ethiopia, discussed the current state of youth programs and the challenge they face in reaching the most vulnerable youth. He pointed to the large number of young girls who migrate to urban centers for work without the support of family or parents and noted that adolescents make up the largest group (55 percent) of orphans as well as victims of sexual abuse and exploitation.

Mabala identified several challenges that programs for youth confront:

- Youth programs tend to focus on messages relating to behavior change"use a condom" or "abstain" - without providing information for decisionmaking and developing skills necessary to acheive the desired outcome.

- Even if adolescents possess the necessary skills and information to adopt protective or healthy reproductive health behaviors, isolation and lack of financial and support structures may play a predominant role in dictating their actual behavior.

- Youth programs often fail to address social norms such as adolescent marriage, early childbirth, and female genital mutilation that are harmful to young people.

- Youth programs miss significant groups of young people. For example, social norms in rural settings often exclude girls from various programs; younger adolescents are often not included or reached by program efforts; and boys are often disproportionately involved in youth centers and engaged by peer educators.
- Issues of gender equity are generally seen as critical, yet difficult to influence.

\section{Services for youth}

Evidence presented at the forum indicates that young people in Africa are at serious risk of adverse reproductive health outcomes, such as HIV infection and unintended pregnancy. Sarah Thomsen, from YouthNet/FHI, highlighted findings from studies of client use of voluntary counseling and testing (VCT) clinics in Haiti and Tanzania, which found that over 60 percent of youth were at risk of HIV and more than 80 percent did not want to become pregnant in the next two years. The studies also demonstrated that young VCT clients did not have an accurate perception of their risk of HIV infection. Ed Scholl, from YouthNet/FHI, mentioned several challenges facing youth

\section{"Young people are not vulnerable because there is HIV. Young people are vulnerable, that's why there is HIV." -Richard Mabala, UNICEF}

as they attempt to access reproductive health services. Providers are often reluctant to supply contraceptives or even reproductive health information to sexually active young people because of cultural norms or misinformed clinical practices. In many places, providers lack the training to communicate effectively with young people seeking reproductive services or information. In addition, youth face financial barriers to accessing services and supplies, as well as physical barriers such as distance to clinics and lack of transportation. 
Program managers and policymakers need to understand the unique needs of youth and the most appropriate means of providing information and services, in order to create a youth-friendly atmosphere and youth-accessible services. Forum participants provided insight into the preferences and needs of adolescents. Asekho Dastile, from Students Partnership Worldwide/South Africa, suggested from her experience that youth are most interested in a welcoming atmosphere that offers privacy and confidentiality. Sudi Biko Matara, from I Choose Life/Kenya, reported that youth often are uninformed about programs and do not know where services are available. According to Judith Senderowitz, an independent consultant, a recent study of adolescent preferences found respect, privacy, confidentiality, short waiting time, and affordable fees were most important to young people. Ed Scholl suggested that youth prefer "one-stop shopping" - that is, access to as many services as possible in one visit.

Experience and evidence from many countries have shown that stand-alone, youthonly services are generally expensive and often not widely used. Examples in which youth-friendly services were provided within existing clinics include the Youth Friendly Services Project in Ghana, Botswana, Tanzania, and Uganda; the FRONTIERS Program studies in Bangladesh, Kenya, Mexico, and Senegal; the Love Life Campaign in South Africa; and the Pathfinder project in Ethiopia. These examples demonstrate that it is feasible to train providers and adapt services to create high-quality youth-friendly services. ${ }^{3}$

${ }^{3}$ Presentations and publications providing additional information on these programs, findings, and lessons learned are available on the Forum CD ROM available from frontiers@ pcdc.org and the YouthNet website, www.fhi.org/en/Youth/ Youth Net/.
Some of the key issues related to provision of reproductive health services for youth, as identified by participants, include:

- Ensuring reproductive health services for youth within existing health systems should be a priority. A recent WHO publication, "Steady, Ready, Go!," identified interventions that include training for service providers, changes in facilities, and promotion of services among youth and community gatekeepers as priorities for large-scale implementation. ${ }^{4}$

- Innovative approaches that meet the needs of the most vulnerable youth should be developed and tested.

- Youth participation should be encouraged in the design and implementation of services. Their participation will increase the quality and accessibility of services and build the capacity of young people.

- Additional effort should be undertaken to integrate reproductive health and HIV services.

- Programs should encourage national health information systems to disaggregate service statistics by age so programs and governments can more accurately monitor use of services.

Some participants expressed concern about provider motivation in dealing with sensitive issues such as services for adolescents. It was suggested that adjustments to service

\footnotetext{
${ }^{4}$ Ross, Dick, and Ferguson (eds.) 2006. "Preventing HIV/ AIDS in young people: A systematic review of the evidence from developing countries (Steady, Ready, Go!)." Geneva: WHO. This document reviews evidence of the effectiveness of interventions to achieve the global goals on HIV/AIDS among young people in developing countries. The intention is to inform the choices of policymakers and program managers, to provide a comprehensive review of the evidence for effectiveness, and to clarify our understanding about "evidence" and develop a standard methodology for reviewing different types of interventions in different settings. The process is a partnership involving organizations such as WHO, UNICEF, UNAIDS, UNFPA, the London School of Hygiene and Tropical Medicine, and others. The full report is available at http://www.who.int/child-adolescent-health/ New_Publications/ADH/TRS/ISBN_92_4_120938_0.pdf
} 
delivery protocols would allow lower-level providers to dispense more reproductive health services. Also, alternative service delivery mechanisms could be explored to reduce the burden on clinics.

\section{School- and}

curriculum-based education

Recently, several groups of independent experts have synthesized evidence on the impact of school- and curriculum-based reproductive health education. Most notably, YouthNet research conducted by Douglas Kirby and colleagues at ETR Associates examined sex and HIV-prevention education programs worldwide, describing their impact and identifying characteristics common to effective programs (2005). Curriculum-based reproductive health education programs were also reviewed as part of WHO’s “Steady, Ready, Go!" initiative.

Both reviews found these programs to be effective when they incorporate certain characteristics. Major findings from the Kirby review include:

- Sex/HIV education programs do not increase sexual activity.

- Some sex/HIV education programs have been shown to delay initiation of intercourse, increase use of condoms/contraception, reduce the number of sexual partners, or reduce the frequency of sex.

- Programs that emphasize abstinence, fewer partners, and use of condoms/contraception are compatible. This information is not conflicting.
- Programs can be effective in serving diverse groups, including males and females, sexually experienced and inexperienced youth, and youth in advantaged and disadvantaged communities.

- Programs may be especially effective among higher-risk youth in disadvantaged communities and in communities where teen pregnancy and STIs are salient issues.

- Programs can be an effective component in more comprehensive initiatives-e.g., those that support academic achievement, family relations, mental and physical health.

Many of these findings were reiterated in discussion related to the Population Council's FRONTIERS youth studies in Kenya and Senegal. These studies, implemented from 1999 to 2003, tested a multisectoral approach - schools, health centers, and the community -to providing reproductive health information and services to adolescents ages 10-19 years old. Presentations provided additional detail on implementation and results of the

\section{"Just as youth are diverse, services must be diverse."}

—Ed Scholl, FHI

two successful programs, both of which are being scaled-up nationally. Rosemary Zulu, from Students Partnership Worldwide, identified lack of acceptance by schools as the most significant barrier to provision of reproductive health education in schools. Finally the presentations highlighted the importance of engaging schools and communities at all stages of planning, design, and implementation. 


\section{Peer education}

Hally Mahler, from YouthNet/ FHI, presented findings from an analysis of peer education programs conducted by Eleanor Maticka-Tyndale. The analysis concluded that peer education can be an effective means of connecting youth to services, increasing their knowledge, decreasing the number of sex partners, and increasing the use of condoms and other contraceptive methods. Evidence was less consistent in measuring an effect on abstinence - either through delaying first intercourse or through secondary abstinence - and effects were more evident among young women than young men. Anta Fall Diagne and Nafissatou Diop, FRONTIERS/Population Council, discussed the development of a peer education component for the FRONTIERS project in Senegal. The Ministry of Education and

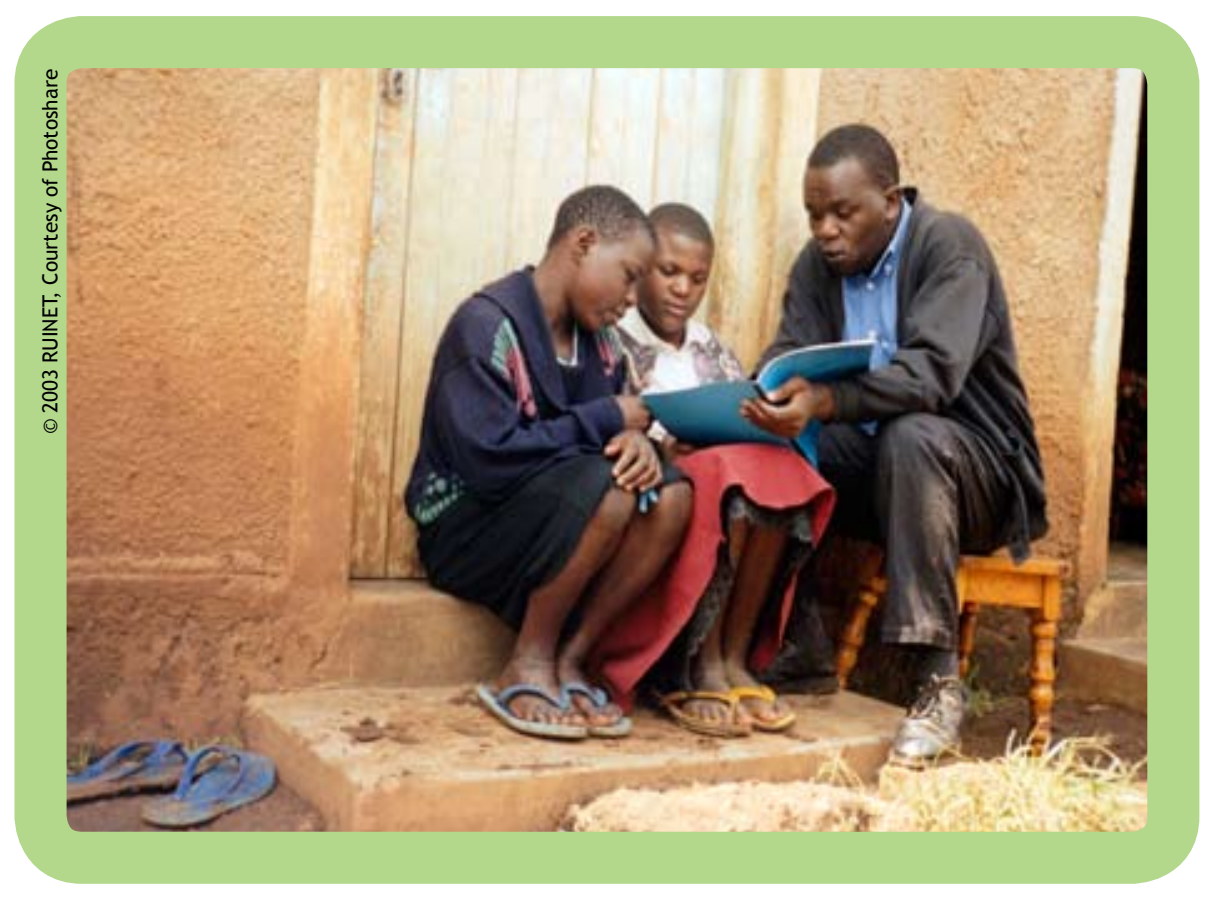

Jones Kilonzo (R) of RUINET, conducts a house-to-house awareness campaign on HIVIAIDS to vulnerable groups in Kenya. Surveys show that though HIVI AIDS awareness in Kenya is high, young people find it difficult to change their sexual behavior.
Ministry of Sport are currently using the curriculum developed by this project. Jerry Aurah, from the National Organization of Peer Educators (NOPE), described the work of this Kenya-based NGO that builds the capacity of organizations and communities to manage and sustain peer-centered programs. NOPE has developed into a self-sustaining organization and provides training to organizations in several African countries. Judith Senderowitz presented findings from a consultative meeting with YouthNet and UNFPA to develop standards in peer education programs.

Tekle-Ab Mekbib, from the Population Council, offered findings from a study in Ethiopia to examine exposure to peer education programs in an urban area where several programs were being implemented. The study found that 20 percent of adolescents were reached by peer educators and 12 percent were reached by youth centers. Both types of programs disproportionately attracted older boys rather than a mix of boys and girls. The study also identified groups of vulnerable youth who were less likely to be reached by progams, for example, domestic workers, married adolescents, and migrant workers.

The presenters highlighted the following issues as priorities for future programs:

- Peer education has the potential to address the needs of vulnerable youth. Emphasis should be placed on creating and measuring program goals.

- In many communities, youth are burdened with financial and social 
responsibilities. In the context of high rates of poverty and unemployment, participation in voluntary programs can place heavy demands on young people's time and resources.

- Peer education presents a gender paradox, in which some programs reach more males than females while others demonstrate greater impact on females. Better understanding of the characteristics and determinants that can predict program impact is required.

\section{Supportive} environments

John Townsend, from the Population Council, outlined a framework for understanding and influencing supportive environments for youth in sub-Saharan Africa. The human ecological framework (Figure 1) permits examination of linkages between levels of environmental contexts. The framework is useful for understanding the diverse contexts in which young people live; identifies factors at each level that are supportive, indifferent, or harmful to youth; suggests strategies for interventions; and emphasizes connections between levels. At the microsystem level, interventions address the unique needs and personalities of individuals. Such interventions may include youth hotlines and individual skills training. Mesosystem interventions involve relationships with and among young people. These interventions may target friends, family, employers, and teachers, including school and peer programs. The exosystem supports larger community networks in which youth may participate. Youth-friendly health services and community violence prevention programs are examples of programs at this level. The macrosystem includes social conventions that influence or affect youth. Policies, those focused on the Millennium Development Goals, and social institutions, such as the media, are involved at this level.

A small group of participants reviewed the ecological framework as it is applied to the prevention of violence (WHO 2004), identified issues and tools useful in addressing the policy environment, identified key stakeholders in supportive environments, discussed case studies, and prepared conclusions and recommendations for presentation to the forum. Participants in this exercise included senior public-sector officials, representatives of donor organizations, senior international resource persons, youth leaders, and representatives of service organizations.

\section{Figure 1: Human Ecological Framework}

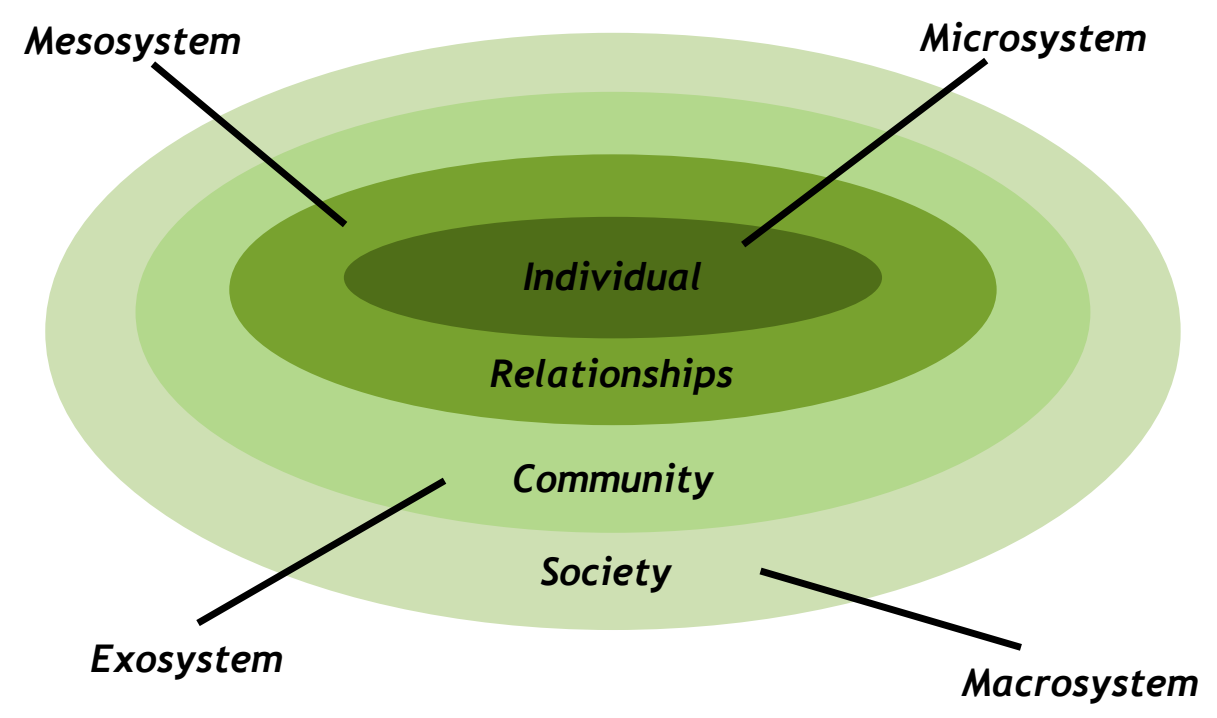

Adapted from Bronfenbrenner, U. 1979. The Ecology of Human Development. Cambridge, MA: Harvard University Press. 


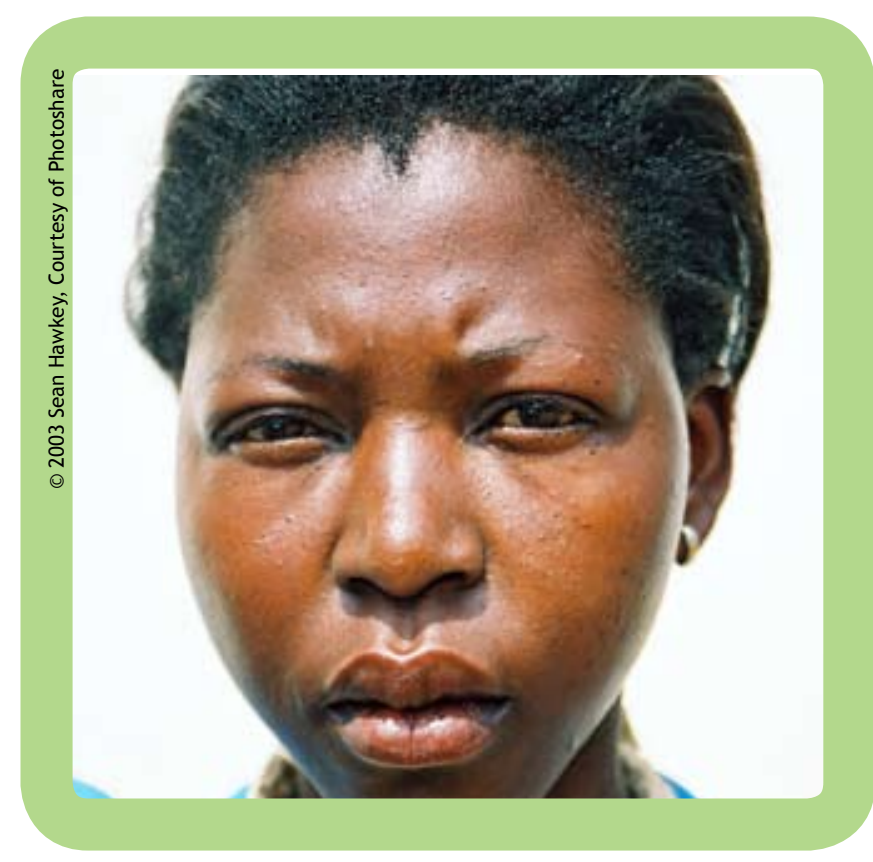

An HIV-positive girl at a center for people living with HIVIAIDS in Lilongwe, Malawi.

These participants grouped their conclusions into three categories: "what we know and examples of what works," "program and research gaps," and "the way forward, recommendations for action." They identified several characteristics or elements of programs with positive experience working at multiple levels of the human ecological framework. Examples include:

- Programs should specify target groups, identify at each stage of implementation who is benefiting and who is left out, and make special efforts to engage the most vulnerable groups.

- Change takes time, especially in creating supportive environments, and political commitment and policy support are required.

- Collaboration and regular feedback facilitate communication. Inter-ministerial working groups and regular meetings were some of the mechanisms used to establish effective communication.

- Programs should draw on existing national and local structures to build supportive environments.
- Interlinked programs with consistent messages that support both services and schools were key to many positive outcomes in the community.

- Programs that focus at the outset on building the capacity of beneficiaries increase their ability to foster community ownership and cooperation. Programs should involve target audiences in research and then use the results to inform the content of programs.

There is limited research demonstrating the impact of multi-level programs on reproductive health outcomes. Nevertheless, broad support for this approach exists based on the premise that political and community involvement is key to building commitment, sustainability, and more effective programs. Participants discussed the difficulty of translating theory into practice and identified and gaps in knowledge and understanding of these programs, including the following:

- A supportive environment is hard to evaluate as the field lacks tools and appropriate indicators.

- We know little about the effects of structural interventions, particularly the timing of expected benefits.

- It is difficult to attribute costs and benefits to broad multisectoral interventions.

- Researchers need to make results more readily available and more comprehensible. Policymakers need to be open to using evidence in decisionmaking.

- Multisectoral programs are demanding because they involve many linkages and stakeholders.

- Scale-up has all the problems of multisectoral programs plus the additional resource requirements.

Participants offered the follow recommendations for creating supportive environments: 
- Foster participation and partnerships at all levels. Partnerships are critical in making a difference in all environments. Understanding the various levels of the human ecological framework is helpful in identifying who should be engaged in partnerships.

- Learn from successful programs and use a range of strategies to share lessons learned, as well as to disseminate best practices, including study tours, south-tosouth exchanges, and websites.

- Support for developing national policies that benefit youth is critical. To be effective, youth themselves need to be involved at the national level so that governments do not isolate the reproductive health needs of youth from other needs and rights.

- At the outset, build capacity of potential beneficiaries and providers to ensure both immediate effectiveness and long-term sustainability.

- In scaling-up, build on existing groups in the community, with the support of advocacy groups and local government.

Ultimately, youth define their own supportive environment. Involvement of youth in identifying and designing programs to address their needs is essential. This point was highlighted by Sudi Biko Matara, from I Choose Life, Kenya, who described the need for positive role models who are dedicated to providing opportunities for youth.

\section{Monitoring and evaluation of youth programs}

The importance of monitoring and evaluating programs was a central theme of the

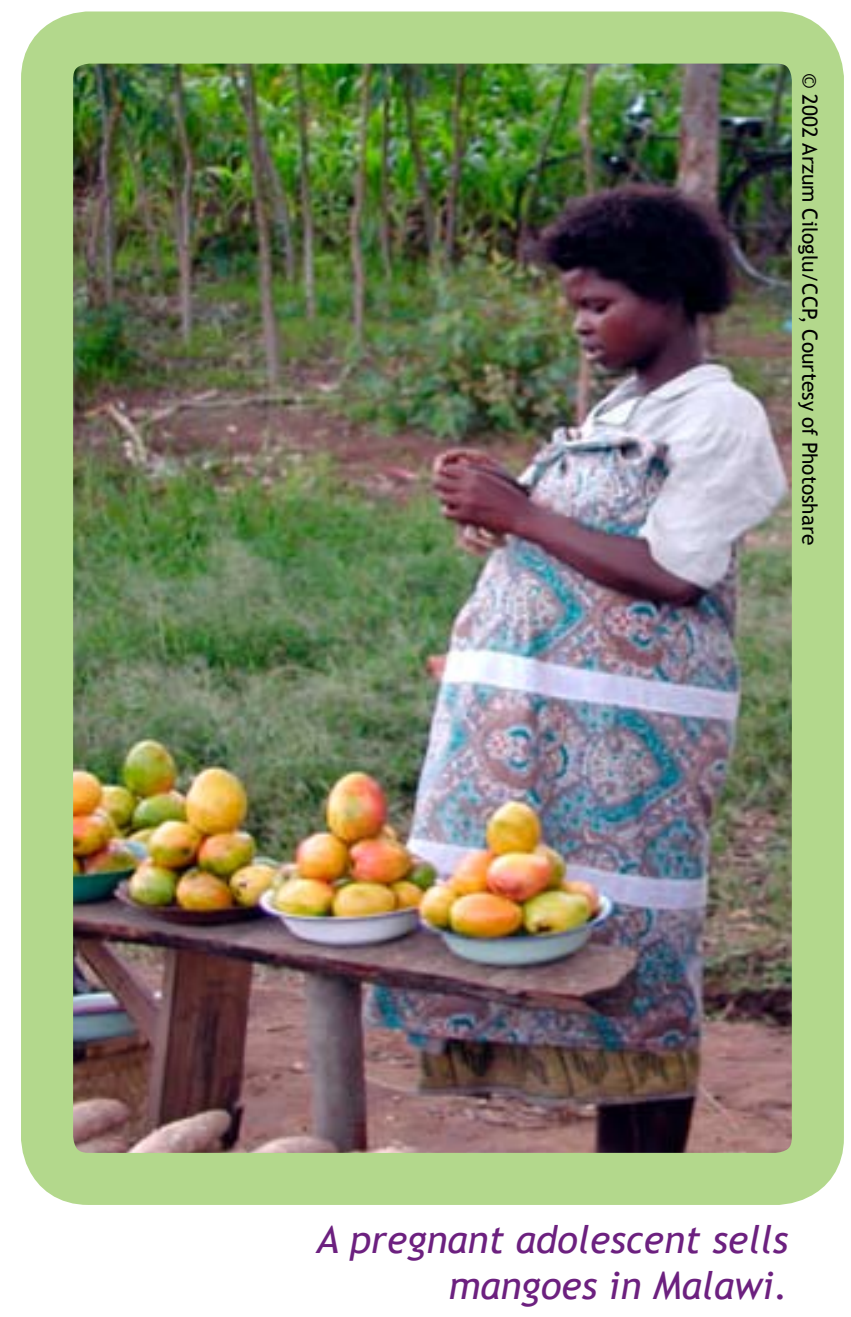

Africa Regional Forum. The lack of, the need for, and the value of evidence were cited in presentations and discussions. Panelists from donor, foundation, and implementing agencies discussed the role of monitoring and evaluation for reporting achievements and impact to donors and stakeholders and as an essential tool for informing and improving programs. The critical nature of impact data was emphasized by Cynthia Lloyd and Venkatraman Chandra-Mouli, who referred to two key documents: Growing Up Global and "Steady, Ready, Go!" These publications have helped develop consensus regarding effective interventions to improve the reproductive health of young people in the developing world. Both presenters also mentioned the dearth of program impact data on youth interventions. 
Participants identified the challenges and future priorities for evaluation and monitoring of programs. Ian Askew, of FRONTIERS/Population Council, Kenya, reviewed conceptual frameworks for monitoring program performance and evaluating program effectiveness, with particular reference to youth reproductive health/HIV programs. Traditionally, monitoring and evaluation have focused on outputs and outcomes. However, there is a pressing need to increase attention to issues of cost analysis and process documentation. Cost analysis should include both cost-benefit analysis and information on the cost of sustaining programs over time. It is not sufficient to evaluate a program without also demonstrating that it is feasible and sustainable. Process documentation includes measuring the intensity of program inputs (i.e., days of training, number of community events, and composition of participation) as well as demonstrating the expected impact of the intervention on intermediate variables (i.e., training increased provider knowledge and improved counseling increased client knowledge).

Several recommendations to improve data collection were offered, including:

- Collecting sensitive information and ensuring accuracy of self-reported behaviors can be facilitated by using audioCASI (computer-assisted self-interviewing). ${ }^{5}$

- Snowball sampling ${ }^{6}$ may be an appropriate means of identifying vulnerable or disenfranchised populations.

\footnotetext{
${ }^{5}$ Audio-CASI is a computer-assisted interviewing technique developed and tested by the Population Council. A paper comparing the results of interviews conducted with audioCASI and those with traditional methods is available at http://www.popcouncil.org/pdfs/wp/168.pdf

${ }^{6}$ Snowball sampling is a technique for developing a research sample where existing study subjects recruit future subjects from among their acquaintances.
}

- Asking background or less sensitive questions can be helpful in preparing respondents prior to addressing sensitive topics.

It is especially difficult to design programs that seek to change social structures in ways that are expected to affect individual outcomes. Programs need to determine in advance the criteria for success: when determination of "success" can be made, what level of change is considered "success," and who has responsibility for declaring "success." Future programs will need to address increasingly difficult issues related to monitoring and evaluation, including sustainability, measuring impact of structural interventions, assessing success of programs that target vulnerability, and use of participatory approaches to monitoring and evaluation.

Ensuring that research and evaluation are held to high standards of ethical review is critical for youth programs. Although several participants experienced conflicting guidance from country and institutional or international review boards, ultimately program managers are responsible for balancing these views and enforcing the highest standard to ensure participant safety. FHI's online course was recommended as additional training on ethics in research. ${ }^{7}$ Managers have responsibility to ensure that programs:

- Demonstrate respect for individuals, allow autonomous participation, and protect the vulnerable. Participants

${ }^{7}$ The Research Ethics Training Curriculum, developed by Family Health International (FHI), provides guidance for international researchers on the establishment of universal ethical standards in designing and implementing research involving human participants. The Research Ethics Training Curriculum for Community Representatives was designed by FHI to educate community representatives about their roles and responsibilities so that they have a stronger voice before, during, and after the research process. Both are available on the FHI website in English, French, Spanish, and Portuguese: http://www.fhi.org/en/RH/Training/trainmat/ethicscurr/index.htm 
highlighted the importance of informed consent and the challenges associated with ensuring consent (via guardian or parent, with formal signatures) while achieving confidentiality.

- Protect participants from harm.

- Maximize benefits from program participation. Discussants specified the role of dissemination and sharing findings with the community and participants to ensure benefits.

- Benefits must outweigh potential risks.

- Control groups should not be excluded from known benefits.

- Approaches taken should have the potential for sustainability.

Participants emphasized the responsibility of the researcher to verify procedures such as appropriate coding, maintaining program focus as outlined to participants and the community, and avoiding collection or disseminating information that could be traced back to individuals or groups within the study population.

\section{Youth participation}

Youth were invited to participate actively in the African Regional Forum. Led by YouthNet, youth participants were encouraged to define their roles as presenters, participants, and resource persons. Young people reported that this preparation allowed them to interact with other forum participants on a professional level. They were able to identify central themes and messages to communicate to other participants.

During the forum youth were involved in making presentations, participating in panels, and engaging in discussions. They also provided feedback to the planning commit- tee at the end of each day. This information assisted organizers in making adjustments to allow for maximum interaction. For example, one request by the young people was to not single them out as "youth participants." They wanted to be viewed as participants of equal status.

Richard Mabala, of UNICEF, cited an example of how involving youth in research can inform programs and empower youth.

In this case study, young people were taught how to examine a problem using research methods. As a result of their involvement, communities saw young people as contributing to society; their role and behavior changed not as a result of formal education but rather through learning a valued skill.

While there is little evidence to measure the effect of youth participation on program impact, most agree that participation is fundamental to effective programs. Maxwell Marx, of FHI, suggested that the need for evidence is moot because most programs consider involvement of participants essential, both in defining needs and in designing approaches. This point was reiterated by Sudi Biko Matara. He suggests that youth programs stress the need for "change," yet

\section{"Comparison is at the heart of a good impact evaluation." -Ian Askew, Population Council}

they are unclear how change should occur. Adolescents are not involved in program development, and as a result adolescents lack the knowledge or skills to achieve real change.

Youth participation faces many challenges. What is the balance between youth-defined needs and the priorities of the donor or program manager? How is consistency of youth participation ensured? Is it appropri- 


\section{"Youth participation is a right and responsibility.”}

-Maxwell Marx, FHI

ate to expect substantial involvement without monetary compensation? One participant suggested that we consider youth participation as a form of partnership to complement the expertise of professionals involved in the implementation of programs. This type of collaborative effort allows the perspective of target groups to guide programs, while ensuring that key lessons of successful approaches guide program effort. ${ }^{8}$

\section{Recommendations}

The following recommendations are derived from the evidence and analysis provided during presentations, group discussions, and working groups at the forum.

\section{Trends in youth behavior and environment}

- Governments, communities, families, and donors should respond to the needs of young people by creating supportive environments and programs to prevent and address the causes of vulnerability and their consequences.

- Programs for youth must improve efforts to identify and meet the diverse needs

\footnotetext{
${ }^{8}$ The "Youth Participation Guide: Assessment, Planning, and Implementation" (see Maxwell et al. 2005 in Appendix 4) provides strategies and tools to develop meaningful youth participation. The Guide aims to increase the level of participation in organizations and programs, and to assist organizations and donors to assess and integrate youth into program and work plan development.
}

reflected within this growing sector of society.

- Given the increased vulnerability and special needs of some subgroups, additional effort should be made to identify these groups and provide reproductive health information and services appropriate to their situation.

- There is a need for increased research and program planning for married adolescents to address issues of maternal mortality and morbidity, gender equity, and contraceptive use.

- Messages promoting condom use as a contraceptive should provide women with a more acceptable negotiating stance with partners than disease prevention alone.

\section{Participation of youth}

- Meaningful participation makes programs more relevant and sustainable and improves general youth development. Youth should be involved in the design, implementation, and evaluation of programs.

- Given the critical role of youth participation in program success, there is a need to develop new methods to measure the level and effects of youth participation on program quality and sustainability.

\section{Services for youth}

- Programs should incorporate multisectoral approaches whenever feasible. At a minimum, youth programs should be linked with other networks concerned with youth, as well as with other efforts to serve the needs of youth in the community.

- To improve quality and accessibility, efforts should be made to train clinic providers and supervisors, remove medical 
and other access barriers, integrate services (especially reproductive health and HIV), and offer as many services under one roof as possible, while referring people to other youth-friendly providers for services not offered. Also, ensure privacy and confidentiality for youth seeking services.

- Documented models of successful and unsuccessful integration experiences are needed to better understand the benefits, processes, and limitations of service integration.

- Programs should work with governments and organizations to ensure the disaggregation of service statistics by age, gender, and other relevant variables to provide managers and policymakers with accurate measures of access to and use of reproductive health services.

- Programs should prioritize taking reproductive health and HIV services directly to youth, rather than building new facilities. Stand-alone, multi-purpose youth centers and clubs often fail to attract large numbers of at-risk youth and are expensive to build and operate.

\section{School- and curriculum-based education, and peer education}

- Keeping youth in school is perhaps the most critical strategy for promoting the successful transition to adulthood. In addition to the academic benefits of schooling, the school environment offers opportunities for social support for the healthy development of youth.

- An annotated database should be created to facilitate the adaptation of school and peer education curricula to support the use and scale-up of evidence-based best practices.

- Designers of peer education programs should be knowledgeable about environments where peer education programs are likely to be most effective, as well as about why certain programs have been unsuccessful.

\section{Supportive environments}

- Understanding transitions to adulthood and the linkages between social structures supporting youth (e.g., national institutions, communities, families, civil society) should be a priority area for research and programs.

- Researchers need to make the results of analysis and synthesis on youth issues more readily available and more comprehensible to stakeholders. Similarly, policymakers need to be more aware of best practices and open to applying evidencebased results in decisionmaking.

- Programs should invest greater resources in documenting and sharing experiences related to fostering supportive environments.

- Tools and indicators should be developed and validated to further the understanding of the characteristics of supportive environments and how to foster them.

- Collaboration, regular feedback, and communication are vital to maintaining a positive working relationship with communities. All programs should develop explicit dissemination strategies that include key stakeholders within the community as well as program beneficiaries.

\section{Monitoring and evaluation}

- Programs should include explicit monitoring and evaluation plans appropriate to the level of available funding for services.

- The lack of process data on program implementation is especially problematic when interpreting impact data, attributing effects to program investments, and 
understanding how intervention strategies are implemented. Programs should incorporate process evaluation indictors into monitoring and evaluation plans to ensure measurement of the effectiveness of their interventions.

- The lack of documentation of negative findings or unsuccessful youth programs limits our understanding of how to improve them. A "safe" forum should be created to allow program directors, researchers, and youth to share experiences of unsuccessful programs.

- Indicators do not adequately address issues of vulnerability of individuals and subgroups and how to identify and measure this factor. Methods are needed to better identify and measure the impact of programs on factors of vulnerability and those most at risk from it.

- Programs in support of youth development and improved reproductive health should be designed with clear and realistic objectives and have goals that are appropriate to the activities, resources, and timeframe available.

\section{Conclusions}

After three days of presentations, discussions, and consensus building, participants came together in a final session to restate their commitment to ensuring universal access to reproductive health education and services for youth and their dedication to working on priority issues identified in the forum. Key themes of the forum were highlighted in closing presentations by Judith Senderowitz and Ryan Smith. Smith reiterated the urgency of the work ahead by reminding participants that half of all new HIV infections occur in young people between ages 10 and 24 .
Participants confirmed that a great deal of experience and evidence has been gained from years of conducting programs for youth. They reiterated the importance of learning from the past, improving programs based on evidence and experience, and scaling-up activities that have proven to be effective. In the final session, participants were invited to highlight salient messages from the forum, discuss follow-up plans, and mention gaps not addressed. Participants' comments included:

- the need to avoid duplication in light of increasingly limited resources;

- opportunities for developing multisectoral approaches that can meet the needs of young people;

- fostering government and community ownership in programs;

- more attention to developing culturally appropriate programs; and

- a commitment to stronger linkages between programs and research.

Participants at the African Regional Forum were unanimous in their support for continued broad-based programs for youth in the region. They called upon countries, donors, communities, and families in sub-Saharan Africa to foster supportive environments for youth, and contribute to the development and scaling-up of accessible, effective, and sustainable reproductive health education and services for youth. Ultimately, the goal of these investments is to promote a successful transition of youth to a healthy, productive adulthood. 


\section{Appendix 1: \\ Participants}

\begin{tabular}{|c|c|c|}
\hline Country & Name & Organization/Agency \\
\hline \multicolumn{3}{|l|}{ Ethiopia } \\
\hline & Worknesh Kereta Abshiro & Pathfinder \\
\hline & Dr. Tesfanesh Belay Adale & Ministry of Health \\
\hline & Wubalem Getachew Adane & Ethiopian Youth Network, Benishangul Gumuz Branch \\
\hline & Abaynesh Biru & Family Health International \\
\hline & Hailu Abebe Desta & Coromia Health Bureau \\
\hline & Sahlu Haile & Packard Foundation \\
\hline & Kidest Lulu & USAID \\
\hline & Richard Mabala & UNICEF \\
\hline & Tekle-Ab Mekbib & Population Council \\
\hline & Wealdegeabreal Girma Nigussie & Tigray Youth Association \\
\hline & Tagel Teshome & Ethiopian Youth Network, Somali Branch Office \\
\hline & Nibretie Workneh & UNFPA \\
\hline \multicolumn{3}{|l|}{ Kenya } \\
\hline & Ian Askew & FRONTIERS/Population Council \\
\hline & Jerry Aurah & National Organization of Peer Educators (NOPE) \\
\hline & Humphres Evelia & Population Council \\
\hline & Mary Gichuru & Centre for British Teachers \\
\hline & Annie Gituto & Ministry of Health \\
\hline & Ahmed Hussain & Department of Children's Services \\
\hline & Lucy Kimondo & $\begin{array}{l}\text { National Coordinating Agency for Population and } \\
\text { Development }\end{array}$ \\
\hline & Merceline Kwamboka & Carolina For Kibera, Binti Pamoja Center \\
\hline & Jennifer Liku & Family Health International \\
\hline & Sudi Biko Matara & I Choose Life \\
\hline & Jane Mbugua & Kenya Girl Guides Association \\
\hline & Eva Muthuuri & PATH \\
\hline & Charles Nzioka & University of Nairobi \\
\hline & Simon Ochieng & Family Health International \\
\hline & Margaret Ojago & Ministry of Gender, Sports, Culture, and Social Services \\
\hline & Joyce Ombeva & FRONTIERS/Population Council \\
\hline & Faith Wanjiku & Carolina For Kibera, Binti Pamoja Center \\
\hline & Alice Wambugu & Population Services International (PSI) \\
\hline & Monica Wanjiru & FRONTIERS/Population Council \\
\hline \multicolumn{3}{|l|}{ Namibia } \\
\hline & Taimi Amaambo & YouthNet \\
\hline
\end{tabular}




\begin{tabular}{|c|c|c|}
\hline \multicolumn{3}{|l|}{ Nigeria } \\
\hline & Ademola Ajuwon & University of Ibadan \\
\hline \multicolumn{3}{|l|}{ Senegal } \\
\hline & Anta Fall Diagne & FRONTIERS/Population Council \\
\hline & Alou Alassane Diop & $\begin{array}{l}\text { Association des Aides Ados et Pairs Educateurs en } \\
\text { Sante de la Reproduction }\end{array}$ \\
\hline & Ndèye Magatte Diop Ly & $\begin{array}{l}\text { Reproductive Health Division/Ministry of Health and } \\
\text { Medical Prevention }\end{array}$ \\
\hline & Ciré Lo & Ministère de la Jeunese \\
\hline \multicolumn{3}{|c|}{ South Africa } \\
\hline & Babychan Arackathara & Catholic Church, Prison Care and Support Network \\
\hline & Asekho Dastile & Students Partnership Worldwide (SPW) \\
\hline & Fr. Michael Hagan & Association of Catholic Tertiary Students (ACTS) \\
\hline & Joachim Jacobs & University of the Western Cape \\
\hline & Pranitha Maharaj & University of KwaZulu-Natal \\
\hline & Sonja Martin & Family Health International \\
\hline & Charles Ngwena & University of the Free State \\
\hline \multicolumn{3}{|l|}{ Sweden } \\
\hline & Sarah Thomsen & YouthNet/Family Health International \\
\hline \multicolumn{3}{|c|}{ Switzerland } \\
\hline & Venkatraman Chandra-Mouli & $\begin{array}{l}\text { Child and Adolescent Health and Development (CAH), } \\
\text { World Health Organization (WHO) }\end{array}$ \\
\hline & Shawn Malarcher & $\begin{array}{l}\text { Reproductive Health and Research (RHR), World Health } \\
\text { Organization (WHO) }\end{array}$ \\
\hline & Iqbal Shah & $\begin{array}{l}\text { Reproductive Health and Research (RHR), World Health } \\
\text { Organization (WHO) }\end{array}$ \\
\hline \multicolumn{3}{|c|}{ Tanzania } \\
\hline & Amy Babchek & United Nations Foundation \\
\hline & Lisa Baldwin & USAID \\
\hline & Vicky Chuwa & USAID \\
\hline & Cuthbert Fungo & $\begin{array}{l}\text { Y-PEER Tanzania Network, Family Life Action Trust } \\
\text { (FLAT) }\end{array}$ \\
\hline & Hilary Gerson & Family Health International \\
\hline & Elizabeth Hizza & University Research Co., LLC, Quality Assurance Project \\
\hline & Lutseso Kayando & Support Makete to Self Support (SUMASESU) \\
\hline & Mama Salma Kikwete & First Lady of Tanzania \\
\hline & Anna Kisesa & UNICEF \\
\hline & Henriette Kolb & EU Commission \\
\hline & Jenny Komrower & National Institute of Medical Research \\
\hline & Michele Lanham & YouthNet/Family Health International \\
\hline & Hally Mahler & $\begin{array}{l}\text { Academy for Educational Development (AED), Tanzania } \\
\text { Marketing and Communications Project (T-MARC) }\end{array}$ \\
\hline & Zaina Maimu & Dutch Embassy \\
\hline
\end{tabular}




\begin{tabular}{|c|c|c|}
\hline & Samwel Matiko & Youth Executive Committee \\
\hline & Neema Meena & Ministry of Labour, Employment \& Youth Development \\
\hline & Yeronimo Mlawa & YAG, Program H \\
\hline & Saumu Mohamed & The National Muslim Council of Tanzania (BAKWATA) \\
\hline & Fatma Mwasa & Tanzania Commission for AIDS (TACAIDS) \\
\hline & Daudi Nasib & YouthNet/Family Health International \\
\hline & Soori Nnko & National Institute of Medical Research \\
\hline & Suzy Nyanda & Students Partnership Worldwide (SPW), Iringa Office \\
\hline & Duncan Odhiambo Onditi & Students Partnership Worldwide (SPW) \\
\hline & Eric Ramírez-Ferrero & YouthNet/Family Health International \\
\hline \multirow[t]{6}{*}{ Zanzibar } & Sihaba Iddi Saadat & Zanzibar AIDS Commission (ZAC) \\
\hline & Clare Shaw & Students Partnership Worldwide (SPW), Iringa Office \\
\hline & Ryan Smith & YouthNet/Family Health International \\
\hline & Matthew Tiedemann & YouthNet/Family Health International \\
\hline & Michelle Weinberger & YouthNet/Family Health International \\
\hline & Pamela White & USAID \\
\hline \multicolumn{3}{|l|}{ Uganda } \\
\hline & Francis Kyateka Mondo & Ministry of Gender, Labor and Social Development \\
\hline & Deus Mukalazi & Young Empowered and Healthy (Y.E.A.H.) \\
\hline & Sereen Thaddeus & USAID \\
\hline & Warren Tukwasibwe & CARE \\
\hline \multicolumn{3}{|c|}{ United Kingdom } \\
\hline & John Cleland & $\begin{array}{l}\text { Centre for Population Studies, London School of Hygiene } \\
\text { and Tropical Medicine }\end{array}$ \\
\hline \multicolumn{3}{|c|}{ United States } \\
\hline & Karen Austrian & Carolina For Kibera, Binti Pamoja Center \\
\hline & Peggy Koniz-Booher & University Research Co., LLC, Quality Assurance Project \\
\hline & Cate Lane & Extending Service Delivery (ESD) Project \\
\hline & Cynthia Lloyd & Population Council \\
\hline & Mahua Mandal & USAID \\
\hline & Maxwell Marx & YouthNet/Family Health International \\
\hline & Tonya Nyagiro & YouthNet/Family Health International \\
\hline & Angela Robertson & USAID \\
\hline & Lori Rolleri & ETR Associates \\
\hline & Ed Scholl & YouthNet/Family Health International \\
\hline & Jane Schueller & YouthNet/Family Health International \\
\hline & Judith Senderowitz & Independent Consultant \\
\hline & Peggy Tipton & YouthNet/CARE \\
\hline & Mercedes Torres & YouthNet/Family Health International \\
\hline & John Townsend & Population Council \\
\hline & Ina Warriner & Independent Consultant \\
\hline
\end{tabular}

18 Building a Better Future for Youth: Learning from Experience and Evidence 


\begin{tabular}{|l|l|l|}
\hline \multicolumn{2}{|l|}{ Zambia } & Adolescent Reproductive Health Advocates \\
\hline & Manda McNarry & Livingstone District Health Management Team \\
\hline & Joseph Pyele & Pact \\
\hline & Rosemary Zulu & Students Partnership Worldwide (SPW) \\
\hline
\end{tabular}




\section{Appendix 2: \\ Presentations}

These presentations are available on the web at http://www.fhi.org/en/Youth/YouthNet/

NewsEvents/AfrRegForum.htm

Keynote presentations

Issues and Profiles of Youth Globally

Cynthia B. Lloyd, Population Council

Youth Programming in Africa: Evidence, Challenges, and Opportunities

Richard Mabala, UNICEF, Ethiopia

Youth Participation and Youth-Adult Partnerships

Maxwell Marx, YouthNet/Family Health International

Perspectives and Strategies for Youth

Programming: Reproductive Health/HIV

Services

Ed Scholl, YouthNet/Family Health International

Perspectives and Strategies for Youth Programming: School and Peer-based Interventions

Mary Gichuru, Centre for British Teachers, Kenya

Perspectives and Strategies for Youth Programming: Supportive Environments

John Townsend, Population Council
Plenary presentations

The Effectiveness of Interventions to Achieve the Global Goals on HIV/AIDS among Young People

Venkatraman Chandra-Mouli, CAH/World Health Organization

The Big Picture: Trends in Protective Behavior among Single Women in 18 African Countries

John Cleland, Centre for Population Studies, London School of Hygiene and Tropical Medicine

Monitoring and Evaluation: Meeting Needs and Expectations Ian Askew, FRONTIERS/Population Council, Kenya

School- and curriculum-based interventions

The Characteristics of Effective HIV Prevention and Sex Education Programs

Lori Rolleri, ETR Associates

Serving the Reproductive Health Needs of Adolescents in Senegal

Anta Fall Diagne and Nafissatou Diop, FRONTIERS/Population Council, Senegal

Working to Scale: Primary School Action for Better Health in Kenya

Mary Gichuru, Centre for British Teachers, Kenya

The Evidence Base on Peer Education Hally Mahler, Academy for Educational Development (AED) 
Differential Exposure to Peer Education

Programs among Adolescents in Addis

Ababa

Tekle-Ab Mekbib, Population Council,

Ethiopia and Annabel Erulkar, Population

Council, Ghana

Scaling Up Peer Education from an NGO

Perspective

Jerry Aurah, National Organization of Peer

Educators, Kenya

Setting Standards in Peer Education

Judith Senderowitz, Independent consultant

\section{Concluding remarks}

Summary Presentations from Sessions

- School-and-curriculum-based education, and peer education

- Youth reproductive health and HIV services

- Supportive and enabling environments for youth

\section{Summary and Conclusions}

Judith Senderowitz and Ryan Smith, Population Fellows Minority-Serving Institutions Initiative

Youth reproductive health/HIV services:

Delivery and access

Synthesis of YouthNet Research on RH/HIV

Services for Youth

Sarah Thomsen, YouthNet/Family Health

International

Research on RH/HIV Services in Mexico,

Kenya, Senegal, Bangladesh

Humphres Evelia, FRONTIERS/Population

Council, Kenya

Health Services: Evidence and Implications

Venkatraman Chandra-Mouli, CAH/World

Health Organization

Youth Friendly Services: Lessons from the

Field and Implications for Scale Up

Judith Senderowitz, Independent consultant

Reaching the Most Vulnerable Youth

Richard Mabala, UNICEF, Ethiopia

Reaching Rural Young Women through

RH/FP Services

Worknesh Kereta Abshiro, Pathfinder,

Ethiopia 


\section{Appendix 3:}

Roundtable discussions

Programme for Supporting Orphans and Vulnerable Children

Mary Gichuru, Centre for British Teachers, Kenya

Lessons Learned from Implementing Youth RH/HIV Programs in FBO Settings

Taimi Amaambo, YouthNet, Namibia

Media/Communications for HIV Prevention in the Age of ART: What Needs to Change?

Sereen Thaddeus, USAID, Uganda

The Importance of Community Involvement in Youth Programming

Cate Lane, ESD Project, United States, and Brian Kayongo, Adolescent Reproductive Health Advocates, Zambia

Gender-based Violence Prevention among High School Students in Ibadan, Nigeria Dr. Ademola J. Ajuwon, Department of Health Promotion and Education, College of Medicine, University of Ibadan, Nigeria

Peer Education on HIV/AIDS Prevention and SARA Integration

Jane Mbugua, Kenya Girl Guides Association

Creating a Culture of Coordination:

Lessons Learned from Tanzania

Eric Ramírez-Ferrero and Michelle

Weinberger, YouthNet, Tanzania
Mapping Safe Spaces for Adolescent Girls in the Kibera Slum of Nairobi, Kenya Merceline Kwamboka and Faith Wanjiku, The Binti Pamoja Center, Kenya

Dual Protection from the Risks of Unwanted Pregnancy and Possible Infection by STIs Including HIV Charles Nzioka, University of Nairobi

WHO Social Science Research Initiative Ina Warriner, United States, and Iqbal Shah, Department of Reproductive Health and Research (RHR)

Uganda's Communication Initiative for Youth

Deus Mukalazi, Y.E.A.H.

Role of Community Dialogues in Addressing Sexual Reproductive Health Challenges of Vulnerable Adolescents Warren Tukwasibwe, CARE, Uganda

YMCA FBO intervention in Kenya Simon Ochieng, FHI, Kenya

School-based HIV/AIDS Education Program

Rosemary Zulu, SPW, Zambia 


\section{Appendix 4: Key documents}

Anderson, Elaine A., Nafissatou Diop, and John W. Townsend. 2006. "Supportive environments for youth in sub-Saharan Africa." FRONTIERS Report. Washington, DC: Population Council.

Askew, Ian, Jane Chege, Carolyne Njue, and Samson Radeny. 2004. "A multi-sectoral approach to providing reproductive health information and services to young people in Western Kenya: The Kenya adolescent reproductive health project," FRONTIERS Final Report. Washington, DC: Population Council. http://www.popcouncil.org/pdfs/frontiers/ FR_FinalReports/Kenya_KARP\%20Adol. pdf

Diop, Nafissatou J. et al. 2004. "Improving the reproductive health of adolescents in Senegal," FRONTIERS Final Report. Washington, DC: Population Council. http://www.popcouncil.org/pdfs/FRONTIERS/FR_FinalReports/Senegal_ARH.pdf

Kirby, D., B.A. Laris, and L. Rolleri. 2005. "Impact of sex and HIV education programs on sexual behaviors of youth in developing and developed countries," Youth Research Working Paper No. 2. Research Triangle Park, NC: Family Health International. http://www.fhi.org/en/Youth/YouthNet/Publications/YouthResearchWorkingPapers.htm
Marx, Maxwell, William Finger, and Hally Mahler (eds.) 2005. "Youth participation guide: assessment, planning, and implementation." Arlington, VA: Family Health International.

http://www.fhi.org/en/Youth/YouthNet/ rhtrainmat/ypguide.htm

National Research Council and Institute of Medicine, Panel on Transitions to Adulthood in Developing Countries, Cynthia B. Lloyd (ed.). 2005. Growing Up Global: The Changing Transitions to Adulthood in Developing Countries. Washington, DC: National Academies Press.

http://www.nap.edu/books/030909528X/html

Palmer, Anne. 2002. "Reaching youth worldwide," Johns Hopkins Center for Communication Programs, 1995-2000, Working Paper No. 6. Baltimore, MD: Johns Hopkins University, Bloomberg School of Public Health Population Communication Services. http://www.jhuccp.org/pubs/wp

Ross, David, Bruce Dick, and Jane Ferguson (eds.). 2006. "Preventing HIV/AIDS in young people: A systematic review of the evidence from developing countries (Steady, Ready, Go!)," WHO technical report series no. 938. Geneva: WHO. http://whqlibdoc.who.int/trs/WHO_TRS 938_eng.pdf

United Nations Population Fund, Youth Peer Education Network (Y-PEER), and Family Health International. 2006. "Standards for Peer Education Programmes." Arlington, VA: Family Health International.

http://www.fhi.org/en/youth/youthnet/publications/peeredtoolkit/standards.htm

WHO. 2004. "Preventing violence: A guide to implementing the recommendations of the World Report on violence and health." Geneva: WHO. 


\section{Appendix 5: \\ Additional resources}

Please see the websites of the following organizations for additional resources:

World Health Organization:

http://www.who.int/reproductive-health/

pages_resources/listing_adolescent.en.html

Population Council:

http://www.popcouncil.org/frontiers/

projects_pubs/topics/youth/youth_afl.html

Family Health International:

www.fhi.org/en/youth/youthnet/publications/

index.htm

For a CD-Rom containing the Africa

Regional Forum on Youth Reproductive Health and HIV report, presentations, key documents, background papers, and additional resources, please send an e-mail to frontiers@pcdc.org. 

Department of Reproductive Health \& Research (RHR) World Health Organization (WHO)

1211 Geneva 27 Switzerland

Email: rhrpublications@who.int www.who.int/reproductive-health

Frontiers in Reproductive Health Program (FRONTIERS) Population Council

4301 Connecticut Ave. N.W., Suite 280

Washington, D.C. 20008 U.S.A

Telephone: (202) 237-9400

Facsimile: (202) 237-8410

Email: frontiers@pcdc.org www.popcouncil.org/frontiers

Family Health International 2101 Wilson Boulevard, Suite 700 Arlington, VA 22201 USA Telephone: (703) 516-9779 Facsimile: (703) 516-9781 Email: publications@fhi.org www.fhi.org

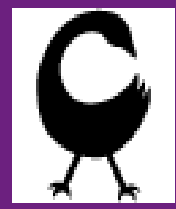

